\title{
Regulatory Mutants of Polyoma Virus Defective in DNA Replication and the Synthesis of Early Proteins
}

\author{
Mary M. Bendig, ${ }^{*}$ Thresia Thomas \\ and William R. Folk \\ Department of Biological Chemistry \\ The University of Michigan \\ Ann Arbor, Michigan 48109
}

\section{Summary}

In polyoma virus the origin of replication, the $5^{\prime}$ ends of early mRNAs, and the initiation codon for early protein synthesis map within an approximately 200 bp region of the genome. We have previously reported the isolation and partial characterization of viable mutants of polyoma virus with deletions in this important regulatory region of the genome. Three of the mutants with large deletions, one of which had signiflcantly altered growth properties, have been further characterized with respect to their nucleotide sequence alterations and their levels of viral DNA replication and of early protein synthesis. The nearly coincident deletions in mutants 17 and 2-19 reduce the capacity of these viruses tó replicate, even in the presence of a coinfecting virus; thus they help define one boundary of the origin of DNA replication. The deletion in mutant $\mathbf{7 5}$ appears to remove sequences that are essential for efficient expression of early genes, but has little or no effect upon DNA replication. Its defect is complemented in trans by wild-type virus. All three mutants eliminate sequences which are candidates for RNA polymerase and ribosome binding sites near the initiation codon for early proteins.

\section{Introduction}

Polyoma virus and other small DNA tumor viruses such as SV4O serve as model systems for studying the mechanisms and regulation of DNA, RNA and protein synthesis in eucaryotic cells. An area of particular interest in the polyoma virus genome is the noncoding region around the origin of replication. The origin of DNA replication is located somewhere within an approximately 200 bp region of the genome, but the precise sequence denoting the site where DNA replication is initiated is unknown (Crawford, Robbins and Nicklin, 1974; Friedmann et al., 1979; Soeda et al., 1979). The sequences encoding the $5^{\prime}$ ends of the early mRNAs and the initiation codon for the three known early proteins are located toward one end of this 200 bp region (Smart and Ito, 1978; Hutchinson et al., 1978; Friedmann et al., 1979; Soeda et al., 1979; Kamen et al., 1980). This region is also likely to contain binding site(s) for polyoma large $T$ antigen, the protein that controls the initiation of DNA replica-

* Present address: Institute für Molekularbiologie II der Universität Zürich, Hönggerberg, 8093 Zürich, Switzerland. tion and the level of early strand transcription (Francke and Eckhart, 1973; Cogen, 1978). Also within this region is a $43 \mathrm{bp}$ sequence that is remarkably similar to sequences near the origins of replication of $\mathrm{BK}$ virus and SV40 virus (70-80\% homology) (see Figure 1) (Friedmann et al., 1979; Soeda et al.). This highly conserved sequence shared by these three viruses has a dyad symmetry that might permit alternative structures to form. In SV40, alterations within this sequence affect DNA replication (Shenk, 1978; Shortle and Nathans, 1979).

In polyoma virus, the Hae II and the Bgl I sites are located approximately midway between this highly conserved sequence and the initiation codon for early protein synthesis (Figure 1). We and others have isolated mutants with deletions of various sizes that include these sites (Bendig and Folk, 1979; Griffin and Maddock, 1979; Magriusson and Berg, 1979; Wells, Hutchinson and Eckhart, 1979). All these mutants are viable, and therefore define a nonessential region. One of the mutants with a large deletion (mutant 75) grows significantly less well than wild-type virus. Two other mutants with large deletions (mutants 17 and 2-19) grow as well or nearly as well as wildtype.

We have further characterized these mutants to determine the nature of their defects. We also report the DNA sequences of these mutants, and thus we are able to correlate the deletion of certain DNA sequences with specific functional alterations.

\section{Results}

\section{DNA Sequence Analysis}

To help define the nucleotide sequence alterations in mutants 17,75 and 2-19, we first cloned and amplified their DNAs in E. coli. Bam HI-cleaved polyoma DNAs were ligated to Bam HI-cleaved pBR322 DNA and then cloned in $\mathrm{E}$. coli $\mathrm{K} 12$. The fragment of DNA including the sequences at the $\mathrm{NH}_{2}$ terminus of the early proteins and the origin of DNA replication (Hpa II fragment 5 of wild-type, mutant 17 and mutant 75 virus and, in subsequent experiments, a Dde I fragment from mutant 2-19) was isolated, ${ }^{32} \mathrm{P}$ end-labeled and sequenced using the modified chemical degradation procedure (Maxam and Gilbert, 1977). The nucleotide sequences of the parent strain of polyoma virus, and of mutants 17,75 and $2-19$, are depicted in Figures 1 and 2 . The deletion in mutant 17 removes 86 nucleotides, leaving intact the 13 nucleotides to the $5^{r}$ side of the ATG codon. The deletion in mutant 2-19 removes 77 nucleotides, leaving intact the 19 nucleotides to the $5^{\prime}$ side of the ATG codon. (The deletion in mutant 2-19 removes a -TCA sequence at one end but leaves a -TCA sequence at another end, and consequently the point of recombination cannot be precisely defined.) The deletion in mutant 75 re- 


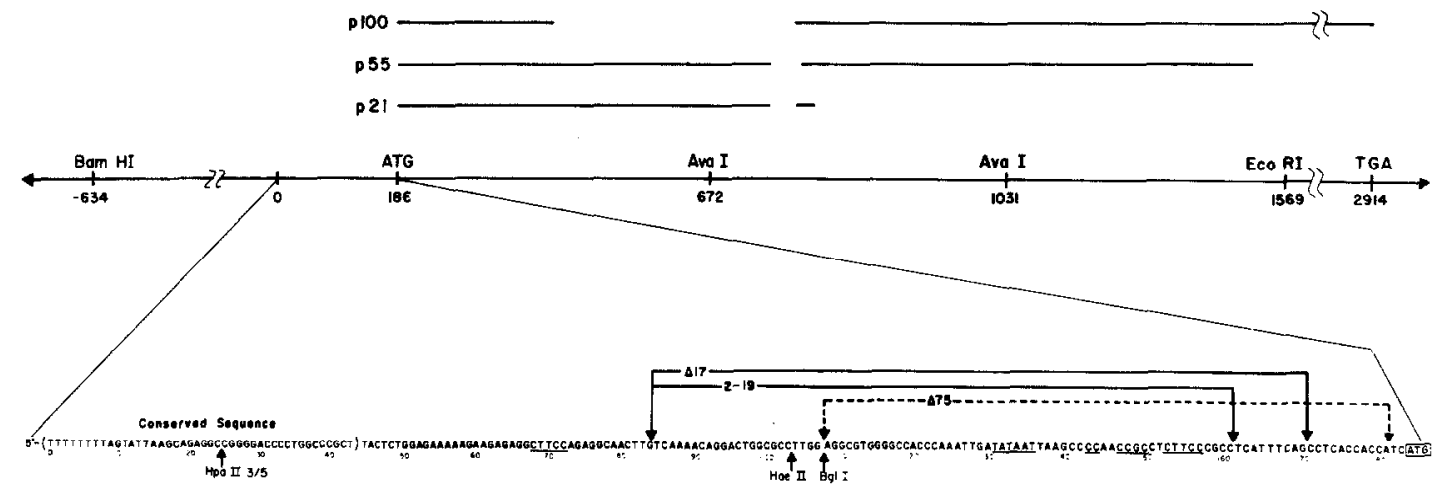

Figure 1. Map of Selected Sequences including the Region near the Origin of DNA Replication of Polyoma Virus

Nucleotides are numbered from a T8 sequence near the origin of DNA replication (Friedmann et al., 1979). The location of the T antigen-coding regions is from Kamen et al. (1980). The nucleotide sequence to the left of the Hpa II $3 / 5$ site is from Friedmann et al. (1979). The sequence to the right of the Hpa II $3 / 5$ site is from our wild-type straln of polyoma virus; the deletions In mutants $17,2-19$ and 75 are shown by the arrows. (Note the ambiguity in placement of the ends of the deletion in mutant 2-19 because of the repeated-TCA sequence.) The conserved sequence between BK, SV4O and polyoma viruses is enclosed in brackets. Potential ribosome binding sites and RNA polymerase binding sites are underlined (Friedmann et al., 1979; Soeda et al., 1979). The ATG codon used to initiate early protein synthesis is enclosed in a box.

moves 78 nucleotides and extends to within 2 bases of the ATG codon. None of the mutants appear to have other sequence alterations in this region. Within the region that is deleted from all three viruses, there are an AT-rich sequence similar to the proposed RNA polymerase II promotor (Gannon et al., 1979), and sequences with the potential of interacting with the $3^{\prime}$ end of 18S rRNA (Hagenbüchle et al., 1978; Friedmann et al., 1979; Figure 1). While these sequences may have some functional significance, it is obvious that they are not absolutely required for virus growth.

\section{Viral DNA Replication}

To determine whether these deletions affect viral DNA replication, secondary whole mouse embryo (WME) cells were infected at equal multiplicities with wildtype polyoma virus or with each of the mutants. The relative amounts of viral DNA synthesized were determined from autoradiographs of agarose gels where viral DNA was separated from cellular DNA. Prior to electrophoresis, the DNAs were digested with one of several single-site endonucleases (Figure 3 ). The results from single infections with wild-type virus or mutant virus are presented in the first section of Table 1. All three mutants exhibit lower levels of viral DNA synthesis than wild-type. Mutant 75 showed the most dramatic reduction in DNA replication, synthesizing 4fold less DNA than wild-type virus during the labeling period. This defect in DNA replication probably accounts for its distinctly smaller plaque size and low virus yields (Bendig and Folk, 1979). Mutant 17 consistently showed a 2 fold reduction in viral DNA synthesis when compared to wild-type. Mutant 17 gives somewhat smaller plaques than wild-type, and its growth at high temperatures $\left(39.5^{\circ} \mathrm{C}\right)$ may be slightly impaired (Bendig and Folk, 1979). The growth curves and plaque morphology of mutant 2-19 were not significantly different from wild-type; however, mutant
2-19 had slightly lower levels of DNA synthesis than did wild-type. This assay is undoubtedly a more sensitive test for replication than either growth curves or plaque morphology.

To determine whether wild-type virus can complement the mutants for their defects in viral DNA replication, WME cells were mixedly infected with equal numbers of mutant and wild-type virus, and the relative amounts of mutant and wild-type DNA synthesized were determined from the intensities of the bands of form I, form II and form III DNA following digestion with $\mathrm{Bgl} \mathrm{I}$ and separation by agarose gel electrophoresis (Figure 3). Results from these mixed infections are given in the second section of Table 1 . All the results presented in Table 1 were taken from the same experiment so that the numbers from separate and mixed infections can be directly compared. Results from five other experiments with WME cells or mouse 3 T 6 cells were qualitatively similar.

Co-infection of WME cells with wild-type virus resulted in a slight increase in the ratio of mutant 17 to wild-type DNA synthesized; however, there was still decidedly less mutant 17 DNA replication than wildtype DNA replication. This lack of full complementation indicates that a significant amount of the reduction of viral DNA synthesis in mutant 17 is the result of a cis mutation. Mutant 17 is presumably deleted for sequences within the origin of DNA replication. For mutant 2-19, co-infection with wild-type virus resulted in a small decrease in the ratio of mutant to wild-type DNA synthesized. As co-infection with wild-type did not enhance the replication of mutant 2-19 DNA, it is probable that its reduced level of viral DNA synthesis is the result of a cis-acting mutation similar to that of mutant 17 . Strong support for the notion that mutants 17 and $2-19$ are defective in a cis-acting function is that the amounts of mutant and wild-type DNA synthesis in co-infected cells were not equal. As the cells 
were co-infected with the same multiplicity of each virus, equal levels of DNA replication would be expected were there not a cis-acting mutation. In contrast to mutants 17 and 2-19, co-infection with mutaht

\section{MUTANT 75}

$G \quad A+G \quad A+C \quad C+T \quad C$

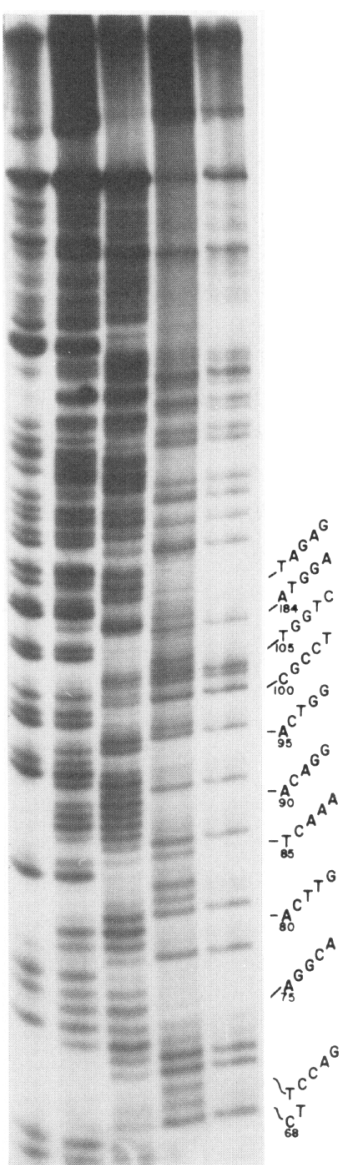

MUTANT 17

G $A+G \quad A+C \quad C+T \quad C$

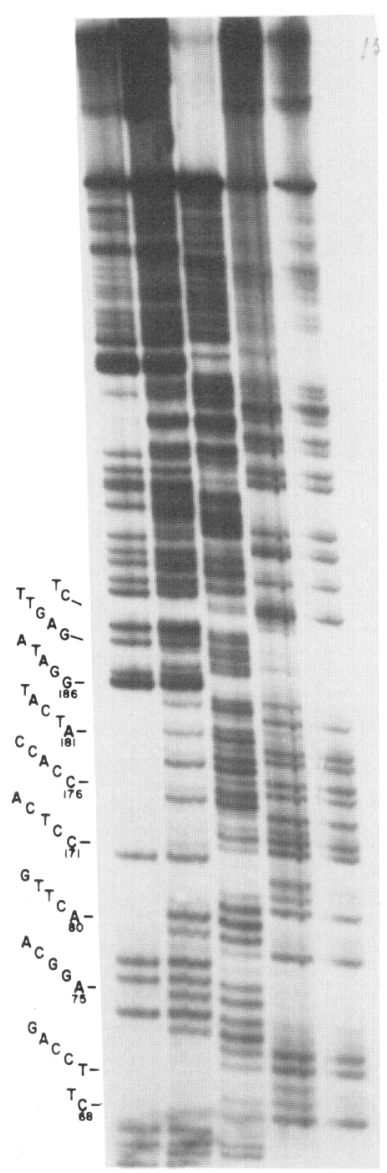

Figure 2. DNA Sequences of Mutants 17 and 75

The autoradiographs display chemically degraded ${ }^{32} \mathrm{P}$ DNAs from mutants 17 and 75 as fractionated on $0.4 \mathrm{~mm}$ thick sequencing gels. Similar data were obtained with wild-type virus (Hpa II-5) or from the opposite strand of mutant 2-19 (Dde I fragment).
75 and wild-type virus resulted in a 3-4 fold increase in the ratio of mutant 75 DNA synthesis to wild-type DNA synthesis; almost equal amounts of the two types of DNA were synthesized. Thus the defect in mutant 75 is complemented in trans by co-infection with wildtype virus, suggesting that the principal defect in replication is the result of insufficient levels of early gene products rather than of an altered origin of DNA replication.

\section{Translation of Early Protein}

The proximity of the deletion in mutant 75 to the initiation codon for early proteins and the results of the complementation assay suggest that the defect in replication in mutant 75 might result from insufficient expression of early genes. To compare the levels of $\mathrm{T}$ antigens synthesized by these mutants, mouse 3T6 cells were infected at equal multiplicities with each virus, the proteins were labeled with ${ }^{35} \mathrm{~S}-$ methionine, and the $T$ antigens were immunoprecipitated and separated on SDS-polyacrylamide gels. To help distinguish virus-coded from cell-coded polypeptides, 3T6 cells were also infected with a viable mutant, mutant 45 , that has a deletion within the coding region for medium and large $T$ antigen. This deletion results in smaller medium and large $T$ antigens but does not affect their level of synthesis (Bendig. Thomas and Folk, 1980). As seen in Figure 4, extracts of cells infected by mutants 2-19 (slot B), 17 (slot D) or 75 (slot $E$ ) contain large and medium $T$ antigens slightly larger than those present in cells infected by mutant 45 (slot C). In this experiment and in others not described, the amounts of the polyoma $T$ antigens in mutant 2-19- and mutant 17-infected cell extracts were measured by densitometric tracings and found to be slightly less than those found in mutant 45- or wild-type-infected cells. However, the amount of all three $T$ antigens synthesized after infection with mutant 75 was reduced $4-5$ fold (slot $E$ ). So mutants $2-$ 19 and 17 have slightly reduced, and mutant 75 greatly reduced, levels of both viral DNA and early protein synthesis.

As suggested above, wild-type virus may comple-
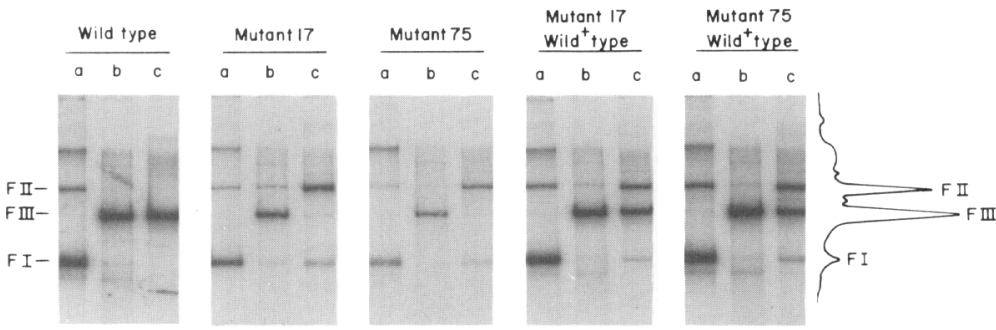

Figure 3. Representative Autoradiographs and a Densitometer Tracing Used to Determine the Relative Amounts of Viral DNA Synthesis after Single or Mixed Infections

WME cells were singly infected with 8 pfu per cell of mutant or wild-type virus. Cells were also mixedly infected with 8 ptu per cell of mutant virus and 8 pfu per cell of wild-type virus. Viral DNAs were labeled, isolated, digested and separated on $1 \%$ agarose gels as described in Experimental Procedures (lane a, undigested; lane b. Eco Rl-digested; lane c, Bgl l-digested). The relative amounts of viral DNA synthesized were determined from densitometer tracings of such autoradiographs. The densitometer tracing of lane $c$ from the mutant 75 plus wild-type virus infection is depicted on the right. Due to contaminating endonucleases in the Bgl I enzyme, most of the Bgl I-resistant mutant DNA appeared as form II DNA rather than as form I DNA following digestion with Bgl I. The low-mobility band near the top of the gel in undigested samples is cellular DNA as it is observed in extracts of uninfected cells. 
Table 1. Viral DNA Synthesis after Single or Mixed Infections

\begin{tabular}{|c|c|c|c|c|}
\hline & \multirow{3}{*}{$\begin{array}{l}\text { Multiplicity } \\
\text { of Infection }\end{array}$} & \multicolumn{3}{|c|}{ Viral DNA Synthesized } \\
\hline & & \multicolumn{2}{|c|}{ Relative Amounts ${ }^{b}$} & \multirow{2}{*}{$\begin{array}{l}\text { Ratio of Relative } \\
\text { Amount } \\
\text { (Mutant/Wild-type }\end{array}$} \\
\hline & & Wild-type & Mutant & \\
\hline \multicolumn{5}{|l|}{ Single infections } \\
\hline Wild-type & 8 & $9.1 \pm 1.5$ & & \\
\hline Mutant 17 & 8 & & $4.6 \pm 0.5$ & 0.50 \\
\hline Mutant 75 & 8 & & $2.3 \pm 0.2$ & 0.25 \\
\hline Mutant 2-19 & 8 & & $7.7 \pm 1.1$ & 0.85 \\
\hline \multicolumn{5}{|l|}{ Mixed infections } \\
\hline \multirow[t]{2}{*}{ Wild-type + mutant 17} & $4+4$ & $6.3+0.2$ & $4.3 \pm 0.2$ & 0.68 \\
\hline & $8+8$ & $6.4 \pm 0.1$ & $3.5 \pm 0.0$ & 0.55 \\
\hline \multirow[t]{2}{*}{ Wild-type + mutant 75} & $4+4$ & $4.3 \pm 0.2$ & $3.2 \pm 0.2$ & 0.74 \\
\hline & $8+8$ & $5.6 \pm 0.2$ & $5.4 \pm 0.3$ & 0.96 \\
\hline \multirow[t]{2}{*}{ Wild-type + mutant 2-19 } & $4+4$ & $5.8 \pm 0.2$ & $3.6 \pm 0.4$ & 0.62 \\
\hline & $8+8$ & $6.7 \pm 0.4$ & $3.6 \pm 0.1$ & 0.54 \\
\hline
\end{tabular}

${ }^{2}$ The virus titers used to calculate the multiplicity of infection were the averages of three independent plaque assays of each stock of virus.

${ }^{-}$The relative amounts of viral DNA synthesized were determined from densitometer tracings as described in Experimental Procedures and as illustrated in Figure 3. They have no units, but are relative to one another in that the same amount of cell extract from each infection was loaded on the gel, exposed to film for the same length of time, and traced with the same amplification on a densitometer. Each value represents the average of two different DNA samples prepared from two plates. Results are from one experiment, but are representative of six independent experiments with WME cells or $3 T 6$ cells.

ment mutant 75 by supplying early proteins. To confirm that this occurs and to determine whether the inability of mutant 75 to synthesize adequate levels of large $T$ antigen persists in cells co-infected with helper virus, it is necessary to compare the amounts of $T$ antigens synthesized from the genomes of mutant 75 and its complementing helper in the same infected cells. This was accomplished by using mutant 45 as the helper in a co-infection experiment similar to that described above. Mutant 45 DNA replication is slightly reduced relative to wild-type, but it is able to complement mutant 75 for viral DNA replication just as does wild-type virus (Table 2), and the large and medium $T$ antigens of mutant 45 can be distinguished from those of mutant 75 by acrylamide gel electrophoresis (Figure 4).

Plates of 3 T 6 cells were singly infected with each mutant or were co-infected with mutant 45 plus mutant 17 or 75 . The infected cells were then examined both for the relative amounts of viral DNA synthesized and for the relative amounts of large $T$ antigens synthesized. The relative amounts of viral DNA synthesis were determined from densitometer tracings of $1 \%$ agarose gels of Eco RI- or Bgl I-digested ${ }^{32} \mathrm{P}$-labeled DNA, as described previously. The results from two experiments using mutant 45 as the complementing virus are presented in Table 2. The ratio of mutant 17 to mutant 45 DNA synthesized did not increase greatly from separate to mixed infections, indicating that mutant 45 is only partially able to complement the defect in DNA replication in mutant 17 . Like wild-type virus, however, mutant 45 was able to fully complement the defect in DNA replication in mutant 75 . The ratio of mutant 75 to mutant 45 DNA synthesized in a mixed infection was approximately one, a 5 fold increase from the ratio of mutant 75 DNA to mutant 45 DNA in separate infections.

The relative amounts of large $\mathbf{T}$ antigens synthesized were determined from densitometer tracings of a 4-8\% discontinuous SDS-polyacrylamide gel of ${ }^{35} \mathrm{~S}-$ labeled immunoprecipitated $\mathrm{T}$ antigens. In this gel system, large $T$ antigen appeared as a doublet band. A similar doublet has been observed by Schaffhausen, Silver and Benjamin (1978). The ratio of normal-sized large $T$ antigen to truncated large $T$ antigen was calculated from the intensities of the upper portions of the doublet bands. As seen in slot $E$ of Figure 5, mixed infection with wild-type virus and mutant 45 resulted in approximately equal amounts of wild-type large $T$ antigen and mutant 45 large $T$ antigen. From slot $F$ of Figure 5 , it is clear that in a mixed infection of mutant 17 and mutant 45 , there was less normalsized large $T$ antigen than truncated large $T$ antigen. Densitometer tracings showed the ratio of mutant 17 to mutant 45 large $T$ antigen in a mixed infection to be 0.3 . This is slightly lower than the ratio of DNAs in separate infections. The reduced level of large $T$ antigen synthesized by mutant 17 in both separate and mixed infections probably reflects the reduced amounts of DNA replication exhibited by this mutant. Slot $G$ of Figure 5 is from a mixed infection of mutant 75 and mutant 45 . Again, there was clearly less nor- 


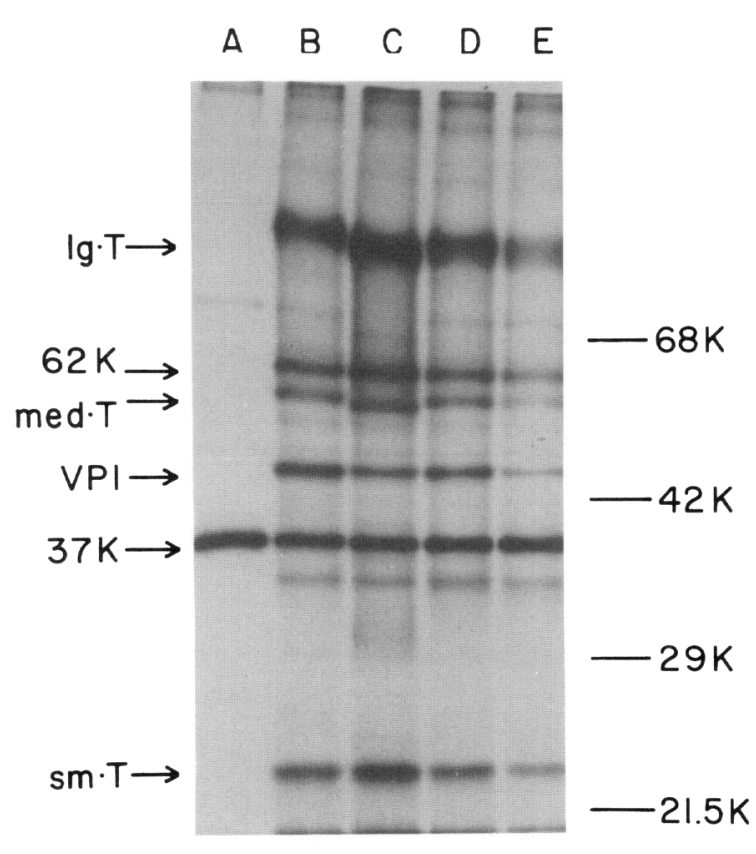

Figure 4. Fluorogram of T Antigens from Mutant-Infected Cells Cells were mock-infected (lane A) or were infected at a multiplicity of 100 pfu per cell with mutant 2-19 (lane B), mutant 45 (lane C), mutant 17 (lane D) or mutant 75 (lane E). The ${ }^{35} \mathrm{~S}$-labeled, immunoprecipitated $T$ antigens were separated on a $5-11 \%$ discontinuous SDSpolyacrylamide gel. The bands of small, medium and large $T$ antigen are indicated on the left. Also pointed out are the band of major vira capsid protein (VP1) and two protein bands ( $37 \mathrm{~K}$ and $62 \mathrm{~K}$ ) that are thought to be unrelated to the $T$ antigens (Hutchinson et al., 1978). Molecular weight markers are indicated on the right.

mal-sized large $T$ antigen than truncated large $T$ antigen. The ratio of mutant 75 to mutant 45 large $T$ antigen in a mixed infection was 0.2 , approximately the same as the ratio of DNA after separate infections. Thus although co-infection with mutant 45 dramatically increased mutant 75 DNA synthesis (Table 2), it did not significantly affect mutant 75 large $T$ antigen synthesis. The defect in DNA replication in mutant 75 is thus likely to be the result of the inability of mutant 75 to synthesize normal levels of large $T$ antigen. This defect is masked, but not corrected by helper virus.

\section{Transcription of Early Genes}

The defect in mutant 75 might occur either at the level of transcription or at the level of translation. To distinguish between these possibilities, and to determine whether the deletion in mutant 17 or in mutant 75 has an effect upon the levels of early gene transcripts, we measured the amounts of viral-specific messages early after infection. These experiments were done with the help of Dr. N. Acheson at the Swiss Institute for Experimental Cancer Research.

Baby mouse kidney cells were infected with wildtype virus, mutant 17 , or mutant 75 and labeled with ${ }^{3} \mathrm{H}$-uridine from $7-10 \mathrm{hr}$ post-infection (in the presence of 5-fluoro-2'-deoxyuridine to inhibit viral DNA replication). The cells were lysed and separated into nuclear and cytoplasmic fractions; the cytoplasmic fractions were further separated (by sucrose gradient sedimentation) into free cytoplasmic RNA, RNA bound to small polyribosomes, and RNA bound to large polyribosomes. RNA was extracted from each fraction and hybridized to total polyoma DNA immobilized on filters. The results are presented in Table 3. Although it is difficult to compare the absolute number of hybridizable counts from one infection to another, there appear to be no large differences between the amounts of viral RNA being synthesized by mutants 17 or 75 and wild-type virus during the early period of infection. There also appear to be no significant differences in the amounts of viral RNA bound to polyribosomes.

Co-reversion of Phenotype and Restriction Pattern To demonstrate that the altered phenotypes of mutants 17 and 75 are due to their deletions surrounding the Bgl I site, revertant genomes were made between a fragment of wild-type DNA that spans the origin of replication and the initiation codon, and a fragment of mutant DNA that contains the remainder of the genome. Ava l-Bam HI-digested wild-type DNA (Figure 1) was separated on a $1 \%$ agarose gel, and the $25 \%$ fragment that includes the origin of replication was extracted from the gel. Mutant DNA was digested with Bam $\mathrm{HI}$, partially digested with Ava I, and then mixed with a molar excess of the purified wild-type fragment. After ligation with T4 DNA ligase, WME cells were infected with the DNA and virus stocks were prepared Appropriate control infections were done to demonstrate that the purified wild-type fragment contained no infectious molecules. The virus stocks were plaque-assayed, and large plaques were picked for further analysis. Since both mutants 17 and 75 have a small-plaque phenotype, large plaques probably arose from recombinants between mutant DNA and the $25 \%$ wild-type DNA fragment.

Six large plaques from each ligation were picked and tested for the restoration of the Bgl I site and for reversion to a wild-type level of viral DNA synthesis. Of the six proposed recombinants between mutant 75 and wild-type DNA, five appeared to be recombinants that contained the Bgl I site and had levels of DNA synthesis similar to wild-type, and one appeared to be a mixture of recombinant and mutant 75 virus, giving a mixture of $\mathrm{Bgl} \mathrm{I-sensitive} \mathrm{and} \mathrm{-resistant} \mathrm{molecules}$ and an intermediate level of DNA synthesis. Of the six proposed recombinants between mutant 17 and wildtype DNA, two appeared to be recombinants that contained the $\mathrm{Bgl} \mathrm{I}$ site and had wild-type levels of DNA synthesis, two were apparently mixtures of recombinant and mutant 17 virus, and two appeared to be mutant 17 virus, since they lacked the Bgl I site and had levels of DNA synthesis comparable to mutant 17. For both mutants, wild-type DNA synthesis re- 
Table 2. Viral DNA Synthesis after Single Infections or Co-infections with Mutant 45

\begin{tabular}{|c|c|c|c|c|}
\hline & \multirow{3}{*}{$\begin{array}{l}\text { Multiplicity } \\
\text { of Infection }\end{array}$} & \multicolumn{3}{|c|}{ Viral DNA Synthesized } \\
\hline & & \multicolumn{2}{|c|}{ Relative Amounts ${ }^{\mathrm{a}}$} & \multirow{2}{*}{$\begin{array}{l}\text { Ratio of } \\
\text { Relative Amounts } \\
\text { (Mutant X/Mutant 45) }\end{array}$} \\
\hline & & Mutant 45 & Mutant X & \\
\hline \multicolumn{5}{|l|}{ Experiment 1} \\
\hline \multicolumn{5}{|l|}{ Single infections } \\
\hline Mutant 45 & 100 & $7.3 \pm 1.9$ & & \\
\hline Mutant 17 & 100 & & $3.8 \pm 0.3$ & 0.52 \\
\hline Mutant 75 & 100 & & $1.5 \pm 0.1$ & 0.18 \\
\hline \multicolumn{5}{|l|}{ Mixed infections } \\
\hline Mutant $45+$ Mutant 17 & $100+100$ & $5.4 \pm 0.8$ & $3.5 \pm 0.7$ & 0.65 \\
\hline Mutant $45+$ Mutant 75 & $100+100$ & $1.4 \pm 0.3$ & $1.5 \pm 0.1$ & 1.10 \\
\hline \multicolumn{5}{|l|}{ Experiment 2} \\
\hline \multicolumn{5}{|l|}{ Single infections } \\
\hline Mutant 45 & 9 & $3.5^{\mathrm{b}}$ & & \\
\hline Mutant 17 & 9 & & $2.8 \pm 0.5$ & 0.80 \\
\hline Mutant 75 & 9 & $0.8^{\mathrm{b}}$ & & 0.23 \\
\hline \multicolumn{5}{|l|}{ Mixed infections } \\
\hline Mutant $45+$ Mutant 17 & $9+9$ & $3.9 \pm 0.5$ & $3.8 \pm 0.5$ & 0.97 \\
\hline Mutant $45+$ Mutant 75 & $6+6$ & $1.3 \pm 0.7$ & $1.3 \pm 0.7$ & 1.00 \\
\hline
\end{tabular}

"The relative amounts of viral DNA synthesis were determined essentially as described in the legend to Table 1 and in Experimental Procedures, except that in these experiments 3T6 cells were substituted for WME cells.

${ }^{\circ}$ These results are based on the analyses of one plate.

turned only when the Bgl I site was restored, supporting the assertion that the deletions at the $\mathrm{Bgl} I$ site account for the altered phenotypes of these mutants.

\section{Discussion}

By comparing the biological alterations in mutants 17 , 2-19 and 75 with their sequence deletions, it is now possible to begin to determine the biological significance of the putative regulatory sequences in this region of the polyoma genome. The deletions in these mutants, although similar in size, appear to have markedly different effects upon the replication and expression of the polyoma genome. Because these deletions include sequences that are unique to each mutant, as well as sequences missing from each mutant, we are able to attribute specific functional alterations to uniquely deleted sequences.

The deletions in mutants 17 and 2-19 cause a defect in viral DNA replication that is not fully complemented in trans. The defect is therefore in a cis-acting element, presumably the origin of replication itself. The deletion in mutant 75 also results in low levels of viral DNA replication; in contrast to that of mutants 17 and 2-19, however, the defect in mutant 75 can be nearly fully complemented by co-infection with wildtype virus or with mutant 45 , a virus with a small deletion at a distant site. The deletion in mutant 75 , therefore, must not extend into the origin of replication. The sequences missing from mutants 17 and 2-
19 but retained in mutant 75 are $40-65$ bp to the early side of the highly conserved sequence of $\mathrm{BK}$, SV 40 and polyoma virus. As mentioned previously, mutations in the conserved sequence in SV4O virus affect DNA replication (Shenk, 1978; Shortle and Nathans, 1979). Our results suggest that in polyoma virus, sequences outside the conserved region contribute to efficient initiation of DNA replication. Although a sampling of three mutants is not highly significant, it is worth noting that there is a significant bias in the sequences excised by the treatment with exonuclease III and S1 nuclease that was used to generate these mutants (Figure 1; Bendig and Folk, 1979). Although the Hae II and Bgl I sites used to open the polyoma genomes occur midway between the highly conserved sequence and the ATG codon, primarily sequences toward the ATG codon were removed. Furthermore, the leftward boundaries of the deletions in mutants 17 and 2-19 are nearly coincident. These two mutants are clearly independent, so this boundary may demarcate a sequence which is of considerable importance to the virus.

Wild-type virus probably complements the defect in mutant 75 viral DNA replication in trans by supplying mutant 75 with adequate levels of early proteins. As mentioned previously, large $T$ antigen is required for the initiation of each round of viral DNA replication (Francke and Eckhart, 1973). Since the deletion in mutant 75 does not extend into the coding sequences for early proteins, the deletion in mutant 75 must 
A $\quad B \quad C \quad D \quad E \quad F \quad G \quad H$

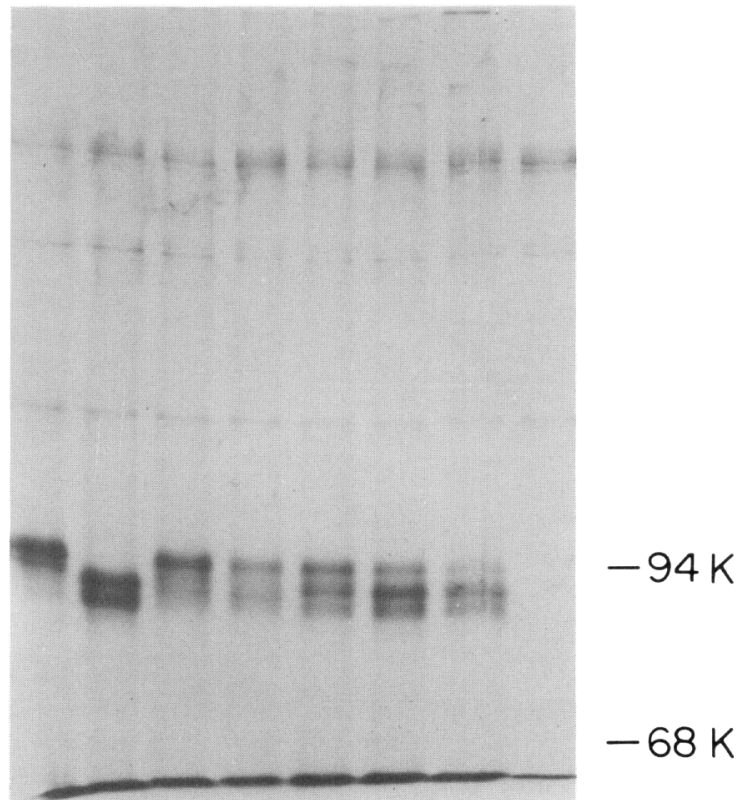

Figure 5. Fluorogram of Large T Antigens from Singly Infected or Mixedly Infected Cells

Cells were singly infected at a multiplicity of approximately 9 pfu per cell with wild-type virus (lane A), mutant 45 (lane B), mutant 17 (lane C), or mutant 75 (lane D). Cells were also mixedly infected with 9 pfu per cell of mutant 45 virus plus 9 pfu per cell of wild-type (lane E), mutant 17 (lane F), or mutant 75 (lane $G$ ). Lane $H$ is from mockinfected cells. After radiolabeling and immunoprecipitation, normalsized and mutant 45-sized large $T$ antigens were separated on a 4$8 \%$ discontinuous SDS-polyacrylamide gel. Molecular weight markers are indicated on the right. remove regulatory sequences that are essential for efficient transcription and/or translation of $T$ antigen. We detected no major reduction in early transcription in mutant 75 , but we did detect significantly lower levels of early protein synthesis. Thus it is probable that mutant 75 is lacking DNA sequences that are essential for efficient translation of early proteins.

Although mutant 17 also had lower levels of early protein synthesis, this slight reduction was probably the result, and not the cause, of its defect in DNA replication. The deletion in mutant 17 ends 13 nucleotides upstream from the ATG codon for early protein synthesis, whereas the deletion in mutant 75 extends to within 2 nucleotides of the ATG codon. Taken together, these results suggest that this eleven nucleotide sequence in early mRNA is important for efficient translation of early proteins. Until the mRNAs of these mutants are examined more carefully, however, and it is determined whether they are properly capped and otherwise processed, it is premature to draw a firm conclusion about the importance of that sequence.

In all three mutants, sequences which are candidates for ribosome and RNA polymerase binding sites have been deleted (Figure 1; Hagenbüchle et al., 1978; Gannon et al., 1979). Although these sequences may be used by wild-type polyoma virus (Friedmann et al., 1979; Soeda et al., 1979), they are clearly not essential. The $5^{\prime}$ ends of wild-type early mRNAs have been mapped near nucleotide 160 , also in the region deleted in mutants 17 and 75 (Kamen et al., 1980; R. Kamen, personal communication). It will

Table 3. Hybridization of Early ${ }^{3} \mathrm{H}-\mathrm{RNA}$ to Polyoma DNA

\begin{tabular}{|c|c|c|c|c|c|}
\hline \multirow[b]{2}{*}{ Virus } & \multirow{2}{*}{$\begin{array}{l}\text { Cell }^{\mathrm{a}} \\
\text { Fraction }\end{array}$} & \multirow{2}{*}{$\begin{array}{l}\text { Input RNA (cmp) } \\
\text { per Hybridization }\end{array}$} & \multicolumn{2}{|c|}{ Hybridized $\mathrm{RNA}^{\mathrm{b}}$ (cpm) } & \multirow{2}{*}{$\begin{array}{l}\% \text { Viral RNA per } \\
\text { Ceil Fraction }^{\circ}\end{array}$} \\
\hline & & & Tube 1 & Tube 2 & \\
\hline \multirow[t]{4}{*}{ Wild-type } & nuclear & $1.2 \times 10^{7}$ & 175 & 217 & 55 \\
\hline & cytoplasmic A & $2.6 \times 10^{6}$ & 65 & 74 & 20 \\
\hline & B & $1.3 \times 10^{6}$ & 60 & 58 & 17 \\
\hline & C & $4.7 \times 10^{5}$ & 33 & 24 & 8 \\
\hline \multirow[t]{4}{*}{ Mutant 17} & nuclear & $1.2 \times 10^{7}$ & 237 & 214 & 69 \\
\hline & cytoplasmic A & $2.5 \times 10^{6}$ & 60 & 56 & 18 \\
\hline & B & $5.3 \times 10^{5}$ & 31 & 12 & 7 \\
\hline & $\mathrm{C}$ & $5.4 \times 10^{5}$ & 24 & 17 & 6 \\
\hline \multirow[t]{4}{*}{ Mutant 75} & nuclear & $1.5 \times 10^{7}$ & 401 & 382 & 66 \\
\hline & cytoplasmic A & $2.7 \times 10^{6}$ & 84 & 81 & 14 \\
\hline & B & $1.3 \times 10^{6}$ & 88 & 82 & 14 \\
\hline & $\mathrm{C}$ & $6.6 \times 10^{5}$ & 35 & 33 & 6 \\
\hline
\end{tabular}

The infected cells were fractionated as described in Experimental Procedures. Cytoplasmic fraction A contains free cytoplasmic RNA; fraction $B$ is RNA bound to small polyribosomes; fraction C is RNA bound to large polyribosomes.

${ }^{b}$ In each hybridization tube, the input ${ }^{3} \mathrm{H}$-RNA was hybridized to two polyoma DNA-containing filters and to one control filter. In tube 1 , the control filter was a blank filter: in tube 2 , the control filter contained $\lambda$ DNA. The hybridizable counts in each tube were calculated by twice subtracting the counts per min on the control filter from the sum of the counts per min on the two polyoma DNA-containing filters.

${ }^{c}$ The percentage of total viral RNA per cell fraction was calculated by dividing the number of hybridizable counts in that cell fraction by the total number of hybridizable counts for all four cell fractions and then multiplying by 100 . 
be of interest to locate the $5^{\prime}$ ends of the early mRNAs of these mutants, now that the normal sequences encoding them have been deleted. A second candidate for an RNA polymerase binding site is located at nucleotides 11-15 (Figure 1; Friedmann et al., 1979). Such AT-rich proposed promoters usually occur 24$26 \mathrm{bp}$ to the $5^{\prime}$ side of the mRNA end; thus this sequence may not function as a primary promoter in the wild-type genome, but it may acquire added significance in the mutants.

\section{Experimental Procedures}

\section{Cell Culture and Virus Infections}

Secondary whole mouse embryo (WME) cells were used to prepare virus stocks and viral DNAs, and in plaque assays. T antigen production and, in some cases, viral DNA synthesis were analyzed in mouse $3 T 6$ cells. The media and the procedures for preparing virus stocks, infecting with viral DNA, and performing plaque assays have been described previously (Folk, 1973; Bendig. Folk and Gibson, 1979). Viral DNAs were purified by a modification of the Hirt procedure (Hirt, 1967; Folk, 1973). Stocks of virus were titered several times to ensure that multiplicities of infection were accurate.

\section{Enzymes and Gel Electrophoresis}

Endonucleases Bgl I and Ava I wore purchased from New England BioLabs. Endonucleases Eco RI, Bam HI, Hpa II, Hinf I and Dde I, and T4DNA ligase, were from Bethesda Research Laboratory. Purified endonuclease Alu I was provided by R. Hart, and polynucleotide kinase by Dr. K. Berkner. Enzyme reactions were carried out as specified by the suppliers or as described by Berkner and Folk (1979). Gel electrophoresis and autoradiography were performed as described by Bendig et al, (1979).

\section{Cloning of Viral DNAs in $\mathrm{E}$. coli}

Polyoma and pBR322 DNAs cleaved with Bam $\mathrm{HI}$ were mixed in a ratio of $3: 1$ ( $1 \mu \mathrm{g}$ DNA total) and incubated overnight at $4^{\circ} \mathrm{C}$ with T4

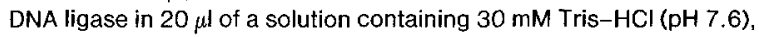
$4 \mathrm{mM} \mathrm{MgCl}, 10 \mathrm{mM}$ dithiothreitol and $0.4 \mathrm{mM}$ ATP. Ligation was checked by gel electrophoresis. The DNAs were transfected into E. coli HB101 (Bolivar et al., 1977) by a modification of the procedure of Mandel and Higa (1970), essentially as described by Cameron et al. (1975). Each transfected culture was allowed to grow in Luria broth for $90 \mathrm{~min}$, and then the cells were plated on L-agar plates containing $25 \mu \mathrm{g} / \mathrm{ml}$ ampicillin. Colonies that were amp pret $^{5}$ were screened for plasmids containing polyoma-pBR322 chimeric DNAs. The orientation and integrity of the polyoma DNA in plasmids was checked by multiple restriction enzyme analysis and by determining that infectious polyoma DNA could be recovered after digestion with Bam HI. P-2 physical containment was used as specified by the NIH Guidelines.

\section{DNA Sequencing}

Polyoma-pBR322 DNAs were extracted from chloramphenicol-amplified cultures by a modified cleared-lysis procedure (Clewell, 19/2) using selective SDS- $\mathrm{NaCl}$ precipitation of the cellular DNA (Hirt, 1967). The DNAs were first deproteinized by incubation with $0.5 \mathrm{mg}$ / $\mathrm{ml}$ pronase followed by phenol extraction, then banded in $\mathrm{CsCl}$ containing ethidium bromide. The purified form I DNA was digested with Hpa II, dephosphorylated with alkaline phosphatase, then separated on $4 \%$ acrylamide gels containing $0.32 \%$ diallytartardiamide (Anker, 1970). The band of polyoma Hpa II-5 was identified (see Israel et al., 1979). In subsequent experiments, the band produced by digestion with Dde I was identified, and both were sliced out from the gel and solubilized in $0.1 \mu \mathrm{M}$ sodium acetate $(\mathrm{pH} \mathrm{5.0)}$ containing $1 \%$ sodium periodate.

The DNA was recovered by passing the dissolved gel through a small DEAE-cellulose column equilibrated in $1 \mathrm{M}$ Tris- $\mathrm{HCl}(\mathrm{pH} \mathrm{8.0)}$.
After washing extensively with $0.1 \mathrm{M}$ Tris $(\mathrm{pH} 8.0), 0.1 \mathrm{mM}$ EDTA the DNA was eluted in $0.1 \mathrm{M}$ sodium acetate $(\mathrm{pH} 5.0)$ with $1.0 \mathrm{M}$ $\mathrm{NaCl}$. It was ethanol-precipitated and redissolved in polynucleotide kinase buffer [50 mM Tris- $\mathrm{HCl}, 10 \mathrm{mM} \mathrm{MgCl}, 5 \mathrm{mM}$ DTT, $0.5 \mathrm{mM}$

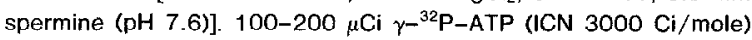
and polynucleotide kinase were added, and the mixture was incubated for $30 \mathrm{~min}$ at $37^{\circ} \mathrm{C}$. The labeled DNA was separated from the untrcatcd triphosphates by chromatography on Sephadex G-75. It was cleaved with a second restriction enzyme, and the asymmetrically labeled fragments were separated on $6 \%$ acrylamide gels containing $0.5 \%$ diallytartardiamide. The DNA fragment of interest was recovered and sequenced by the modified chemical degradation procedure of Maxam and Gilbert (1977). Reactions specific for G, AG, CT, C and $\mathrm{AC}$ were carried out tor $20 \mathrm{~min}$ to determine sequences near the $5^{\prime}$ end of fragment, and for $5 \mathrm{~min}$ to determine sequences far from the $5^{\prime}$ end. Polyacrylamide-bisacrylamide gels $(8,15$ and $20 \% ; 0.4 \mathrm{~mm}$ thick; Sanger and Coulson, 1978) were used to fractionate the products.

\section{Quantitation of Viral DNA Synthesis}

Duplicate $60 \mathrm{~mm}$ plates of confluent WME celis were singly infected with either wild-type or mutant virus. Duplicate plates were also mixedly infected with equal numbers of wild-type and mutant virus. After $12 \mathrm{hr}$ at $33^{\circ} \mathrm{C}$, the medium was changed to a low-phosphate medium containing $10 \mu \mathrm{Ci} / \mathrm{ml}^{32} \mathrm{P}$-orthophosphate. After a $24 \mathrm{hr}$ labeling period, the viral DNA was harvested by the Hirt procedure. Equal volume samples from the Hirt supernatants were digested with Eco RI or Bgl I. The digcsted samples, as well as undigested control samples, were electrophoresed through $1 \%$ agarose gels. Autoradiograms of the gels were scanned with an ORTEC densitometer, and the areas under the peaks were delermined using a Numorics Corporation Graphics Calculator. For single infections with either wildtype or mutant virus, the relative amounts of viral DNA synthesized were determined from the areas under the peaks corresponding to Eco RI-generated form III DNA. For the mixed infections, the quantities of wild-type and mutant DNAs were calculated from the tracings of Bgl l-digested samples. The amount of Bgl I-resistant mutant DNA was determined from the areas under the peaks corresponding to form I and form II DNA. The area under the peak corresponding to form III DNA was used to determine the amount of Bgl I-sensitive wildtype DNA. Appropriate controls were done to demonstrate that the digestions were complete, that the mutant DNA was Bgl l-resistant, and that the wild-type DNA was Bgl I-sensitive

\section{Transcriptional Analysis}

Primary baby mouse kidney (BMK) cells were infected with wild-type or mutant virus at a multiplicity of 20-40 pfu per cell. The infected cells were labeled with $500 \mu \mathrm{Ci}$ of ${ }^{3} \mathrm{H}$-uridine per $88 \mathrm{~mm}$ petri dish from 7-10 hr post-infection. To prevent DNA synthesis, 5-fluoro-2'deoxyuridine $\left(6 \times 10^{-5} \mathrm{M}\right)$ was present throughout the period after infection. At $10 \mathrm{hr}$ post-infection, the cells were lysed with $0.5 \%$ Nonidet P-40 and the nuclear and cytoplasmic tractions were separated by centrifugation at $1500 \times \mathrm{g}$ for $3 \mathrm{~min}$. The cytoplasmic extracts were further fractionated by layering the samples on a $30 \mathrm{ml}$ $15-40 \%$ sucrose gradient with a $3 \mathrm{ml} 55 \%$ sucrose cushion and centrifuging for $1 \mathrm{hr} 45 \mathrm{~min}$ at $80,000 \times \mathrm{g}$. The gradients were collected and analyzed in an ISCO fraction collector and absorbance monitor. Based on the absorbance plot, each gradient was divided into three sections: the top section, which contained no polyribosomes; the middle section, which contained small polyribosomes from two to approximately seven ribosomes per mRNA; and the bottom section, which contained large polyribosomes with more than seven ribosomes per mRNA. RNA was phenol-extracted from the nuclear cell fraction and from the three cytoplasmic cell fractions representing free cytoplasmic RNA, RNA bound to small polyribosomes, and RNA bound to large polyribosomes. The extracted RNA was then hybridized in $50 \%$ formamide to intact polyoma DNA bound to nitrocellulose filters. After 4 days at $37^{\circ} \mathrm{C}$, the filters were rinsed, treated with RNAase, rinsed again, and counted. For a more detailed description of these procedures, see Acheson and Miéville (1978). 


\begin{abstract}
Analysis of T Antigens
Cultures of 3 T 6 cells were infected at equal multiplicities with mutant or wild-type virus. In some experiments, cells were also mixedly infected with equal number of two different mutants. After a $1 \mathrm{hr}$ absorption period, fresh medium was added and the infected cells were incubated at $33^{\circ} \mathrm{C}$ for approximately $42 \mathrm{hr}$. The cells were then radiolabeled for $4 \mathrm{hr}$ with ${ }^{35} \mathrm{~S}$-methionine $(100 \mu \mathrm{Ci} / \mathrm{ml})$ and harvested according to the procedure of Hutchinson, Hunter and Eckart (1978). Immunoprecipitation of the radiolabeled cell extracts was carried out using a modified Staphylococcus protein A procedure (Hutchinson et al., 1978). Anti-polyoma tumor serum was provided by Dr. T. Benja$\mathrm{min}$. The immunoprecipitates were electrophoresed through a discontinuous SDS-polyacrylamide gel (Studier, 1973), which was then stained and prepared for fluorography (Bonner and Laskey, 1974). The proteins used as molecular weight markers were phosphorylase b $(94 \mathrm{~K})$, bovine serum albumin (68K), ovalbumin ( $42 \mathrm{~K})$, carbonic anhydrase (29K) and soybean trypsin inhibitor (12.5K)
\end{abstract}

\section{Acknowledgments}

We are grateful for advice and help in the transcription studies provided by Dr. N. Acheson, and for advice on the use of diallytartardiamide gels from Mr. M. Nelson. We thank Mr. G. LePlatte and Ms. R. White for preparing mouse embryo cultures, and Dr. T. Benjamin for the gift of the polyoma tumor rat antiserum. Support from the National Cancer Institute, from the American Cancer Society and from a USPHS training grant is gratefully acknowledged.

The costs of publication of this article were defrayed in part by the payment of page charges. This article must therefore be hereby marked "advertisement" in accordance with 18 U.S.C. Section 1734 solely to indicate this fact.

Received December 11, 1979; revised February 14, 1980

\section{References}

Acheson, N. H. and Miéville, F. (1978). Extent of transcription of the E. strand of polyoma virus DNA during the early phase of productive infection. J. Virol. 28, 885-894.

Anker, H. S. (1970). A solubilizable acrylamide gel for electrophoresis. FEBS Letters 7, 293.

Bendiy, M. M. and Folk, W. R. (1979). Deletion mulants of polyoma virus defining a nonessential region between the origin of replication and the initiation codon for early proteins. J. Virol. 32, 530-535.

Bendig, M. M., Folk, W. R. and Gibson, W. (1979). Polyoma viruses with mutations at endonuclease Hind II site 1: alterations at the $\mathrm{COOH}$ terminus of VP1. J. Virol. 30, 515-522.

Bendig, M. M., Thomas, T. and Folk, W. R. (1980). Viable deletion mutants in the medium and large T-antigen coding sequences of the polyoma virus genome. J. Virol. 33, 1215-1220.

Berkner, K. L. and Folk, W. R. (1979). A map of the sites in the polyoma genome cleaved by endonuclease Alul. Virology $92,482-$ 292.

Bolivar, F., Rodriguez, R. L., Greene, P. J., Betlach, M. C., Heyneker, H. L. and Boyer, H. W. (1977). Construction and characterization of new cloning vehicle: II; A multipurpose cloning system. Gene 2, 95113.

Bonner, W. M. and Laskey, R. A. (1974). A film detcction method for tritium-labelled proteins and nucleic acids in polyacrylamide gels. Eur. J. Biochem. 46, 83-88.

Cameron, J. R., Panasenko, S. M., Lehman, R. I. and Davis, H. W. (1975). In vitro construction of bacteriophage $\lambda$ carrying segments of the Escherichia coli chromosome: selection of hybrids containing the gene for DNA ligase. Proc. Nat. Acad. Sci. USA 72, 3416-3420.

Clewell, D. B. (1972). Nature of Col $E_{1}$ plasmid replication in Escherichia coli in the presence of chloramphenicol. J. Bacteriol. 110 , 667-676

Cogen, 9. (1978). Virus-specific early RNA in 3 T 6 cells infected by a tsA mutant of polyoma virus. Virology $85,222-230$.
Crawford, L. Y., Robbins, A. K. and Nicklin, P. M. (1974). Location of the origin and terminus of replication in polyoma virus DNA. J. Gen. Virol. 25, 133-142.

Folk, W. R. (1973). Induction of virus synthesis in polyoma-transformed BHK-21 cells. J. Virol. 2, 424-431.

Francke, B. and Eckhart, W. (1973). Polyoma gene function required for viral DNA synthesis. Virology 55, 127-135.

Friedmann, T., Esty, A., LaPorte, P. and Deininger, P. (1979). The nucleotide sequence and genome organization of the polyoma early region: extensive nucleotide and amino acid homology with SV40. Cell 17, 715-724

Gannon, G., OHare, K., Perrin, F., LePennec, J. P., Benoist, C., Cochet, M., Breathnach, R., Moyal, A., Garapin, A., Cami, B. and Chambon, P. (1979). Organization and sequences at the $5^{\prime}$ end of a cloned complete ovalbumin gene. Nature 278, 428-434.

Griffin, B. E. and Maddock, C. (1979). New classes of viable deletion mutants in the early region of polyoma virus. J. Virol. 31, 645-656.

Hagenbüchle, O., Santer, M., Steitz, J. A. and Mans, R. J. (1978). Conservation of the primary structure at the $3^{\prime}$ end of $18 S$ rRNA from eucaryotic celis. Cell 13, 551-563.

Hirt, B. (1967). Selective extraction of polyoma DNA from infected mouse cell cultures. J. Mol. Biol. 26, 365-369.

Hutchinson, M. A., Hunter, T. and Eckhart, W. (1978). Characterization of $\mathrm{T}$ antigens in polyoma-infected and transformed cells. Cell 15 , 65-77.

Israel, M. A., Chan, H. W., Rowe, W. P. and Martin, M. A. (1979). Molecular cloning of polyoma virus DNA in Escherichia coli: plasmid vector system. Science 203, 883-887.

Kamen, R., Favaloro, I., Parker, J., Treisman, R., Lania, L., Fried, M. and Mellor, A. (1980). Comparison of polyoma virus transcription in productively infected mouse lines and transformed rodent cell lines. Cold Spring Harbor Symp. Quant. Biol., in press.

Magnusson, G. and Berg, P. (1979). Construction and analysis of viable deletion mutants of polyoma virus. J. Virol. 32, 523-529.

Mandel, M. and Higa, A. (1970). Calcium-dependent bacteriophage DNA infection. J. Mol. Biol. 53, 159-162.

Maxam, A. and Gilbert, W. (1977). A new method for sequencing DNA. Proc. Nat. Acad. Sci. USA 74, 560-564.

Sanger, F. and Coulson, A. R. (1978). The use of thin acrylamide gels for DNA sequencing. FEBS Letters 87, 103-110.

Shaffhausen, B. S., Silver, J. E. and Benjamin, T. L. (1978). Tumor antigen(s) in cells productively infected by wild-type polyoma virus and mutant NG-18. Proc. Nat. Acad. Sci. USA 75, 79-83.

Shenk, T. (1978). Construction of a viable SV40 variant containing two functional origins of DNA replication. Cell 13, 791-798.

Shortle, D. and Nathans, D. (1979). Regulatory mutants of Simian virus 40: constructed mutants with hase substitutions at the origin of DNA replication. J. Mol. Biol. 131, 801-817.

Smart, J. E. and Ito, Y. (1978). Three species of polyoma virus tumor antigens share common peptides probably near the amino termini of the proteins. Cell 15, 1427-1437.

Soeda, E., Arrand, J. R., Smolar, N. and Griffin, B. E. (1979). Sequence from early region of polyoma virus DNA containing viral replication origin and encoding small, middle and (part of) large $T$ antigens. Cell 17, 357-370.

Studier, F. W. (1973). Analysis of bacteriophage T7 early RNAs and proteins on slab gels. J, Mol. Biol. 79, 237-248.

Wells, R. D., Hutchinson, M. A. and Eckhart, W. (1979). Isolation and characterization of polyoma viruses genomes with deletions between the origin of virat DNA replication and the site of initiation of translation in the early region. J. Virol. 32, 517-522. 